Aurelia Journal
(Authentic Research of Global Fisheries Application Journal)
p-ISSN: 0000-0000
e-mail: aurelia.journal@gmail.com

\title{
PERANCANGAN LAMPU LIGHT EMITTING DIODE (LED) PEMIKAT IKAN
}

\section{LIGHT EMITTING DIODE (LED) LIGHTING PLANNER}

\author{
Boby Wisely Ziliwu ${ }^{1 *}$, Rizqi Ilmal Yaqin ${ }^{1}$, Muhammad Nur Arkham¹, Hamdu Azrawi Daulay ${ }^{1}$ \\ ${ }^{1}$ Politeknik Kelautan dan Perikanan Dumai, Dumai, Indonesia \\ *Korespondensi: bobyziliwu@gmail.com (BW Ziliwu) \\ Diterima 13 Juli 2019 - Disetujui 12 September 2019
}

\begin{abstract}
ABSTRAK. Perkembangan dalam penangkapan ikan akhir-akhir ini banyak dilakukan salah satunya untuk menarik daya tarik ikan menggunakan lampu LED (Light Emitting Diode). Hal ini bertujuan untuk memikat sejumlah ikan, disebabkan ikan-ikan menyukai warna terang. Perkembangan ini dikenal dengan istilah ligth fishing. Pada awalnya sumber cahaya yang digunakan dalam upaya penangkapan ikan adalah menggunakan obor, namun seiring perkembangan pesatnya ilmu pengetahuan dan teknologi mulailah digunakan lampu minyak/kerosene, lampu karbit, perkembangan terakhir dengan penggunaan lampu listrik. Akhrnya ditemukanlah ide untuk membuat lampu LED untuk memikat ikan-ikan. Bisa digunakan dua metode dalam penyalaannya yaitu menggunakan aki yang bertegangan 24 volt dan menggunakan Genset. Hasilnya penangkapan ikan dengan menggunakan lampu LED, jumlah ikan yang ditangkap bisa lebih banyak dibanding menggunakan obor maupun lampu listrik.
\end{abstract}

KATA KUNCI: Lampu LED; Perancangan; Ikan.

ABSTRACT. There have been many developments in fishing lately, one of which is to attract fish using LED lights (Light Emitting Diode). It aims to attract a number of fish, because the fish like bright colors. This development is known as ligth fishing. Initially the light source used in fishing efforts was to use a torch, but as the rapid development of science and technology began to be used oil lamps / kerosene, carbide lamps, the latest developments with the use of electric lights. Finally the idea was found to make LED lights to lure fishes. Two methods can be used in ignition, namely using a 24 volt battery and using a generator. The result is fishing using LED lights, the number of fish caught can be more than using a torch or electric lights.

KEYWORDS: LED Lamp; Design; Fish.

\section{Pendahuluan}

Perkembangan perikanan salah satunya terjadi karena perkembangan pengetahuan mengenai fish behavior seperti beberapa jenis ikan ternyata tertarik dengan cahaya. Perkembangan penangkapan menggunakan alat bantu cahaya berkembangan terus yang kemudian dikenal dengan ligth fishing. Pada awalnya sumber cahaya yang digunakan dalam upaya penangkapan ikan adalah obor, namun seiring perkembangan ilmu dan pengetahuan teknologi mulailah digunakan lampu minyak/kerosene, lampu karbit dan perkembangan begitu pesat banyak armada-armada perikanan yang menggunakan lampu sampai ribuan bahkan puluhan ribu watt. Tetapi masalah yang terjadi adalah apakah penggunaan lampu yang begitu banyak jumlahnya dan begitu besar dayanya sudah efektif, padahal biaya yang dikeluarkannya tidaklah sedikit. Dari hasil penelitian sebelumnnya dinyatakan bahwa nilai iluminasi (lux) suatu sumber cahaya akan menurun dengan meningkatnya jarak 
dari sumber cahaya tersebut, dan nilainya berkurang apabila cahaya tersebut masuk ke dalam air karena mengalami pemudaran (Ben Yami, 1976). Selain itu fakta yang terjadi di Pelabuhan Ratu, penggunaan alat tangkap bagan mengalami kecenderungan yang menurun selama periode 2006-2010. Penggunaan alat tangkap bagan di perairan Pelabuhan Ratu pada tahun 2006 adalah sebesar 263 unit namun pada tahun 2009 menurun drastis menjadi 23 buah.

Penurunan tersebut dimungkinkan karena adanya pengaruh kebijakan pemerintahan dalam konversi minyak tanah ke gas elpiji $3 \mathrm{~kg}$, yang mengakibatkan harga minyak tanah melambung tinggi sehingga biaya operasional bagan mengikat. Berdasarkan permasalahan tersebut, para peniliti mulai mengembangkan lampu bawah air untuk mengurangi besar penurunan nilai iluminasi yang disebabkan oleh pemudaran akibat perbedaan media rambat cahaya dan mengurangi pemborosan energi untuk penggunaan lampu sebagai alat bantu penangkapan. Pengembangan tersebut melalui penggunaan langsung lampu bawah air sehingga tidak terjadi lagi suatu pembiasaan maupun pembelokan cahaya. Kondisi ini diharapkan penggunaan besar sumber cahaya akan lebih efektif dan efisien. Teknologi Lacuba sudah diketahui penggunaannya, yaitu sejak tahun 1990-an. Namun penggunaan jenis lampu LED masih belum banyak diuji cobakan. Pemilihan lampu LED didasarkan pada energi yang digunakan jauh lebih hemat. (S.C Shen \& H.J Huang, 2012) percobaan penggunaan lampu LED untuk penangkapan mengurangi konsumsi BBM sekitar 15-17\%. Penilitian ini memiliki beberapa tujuan, yaitu medesain dan mengkonstruksi lampu LED bawah air, menganalisis kekuatan material bahan yang digunakan, menganalisis besar iluminasi dan sebaran cahaya yang dihasilkan dari lampu, dan mendeskripsikan hasil uji coba penangkapan dengan lampu LED bawah air. Dalam penelitian ini hanya untuk membuktikan bahwa lampu LED kontruksi mampu menghasilkan/mengikat ikan dan layak dikembangkan lebih lanjut.

\section{Metode}

Desain awal alat dibangun untuk penggunaan di dalam air yang bertujuan untuk mengurangi pemudaraan yang disebabkan perbedaan media rambat cahaya. Oleh karena itu pemilihan bahan juga sangat diperhatikan terutama untuk melindungi bagian dari lampu yang terendam dalam air. Hal senada dikemukakan oleh Callister (2004) \& Smith (2006) bahwa dalam merancang atau mendesain sebuah produk terdapat persyaratan terkait dengan sifat dari produk yang ingin dirancang, pemilihan material menjadi salah satu yang harus dipertimbangkan dan harus memperhatikan fungsi (function), batasan (constrain), tujuan (objective), dan variabel bebas (free variables). Selain itu lampu juga dirancang untuk memudahkan penggunanya atau nelayan dalam mendeteksi keberadaan ikan sehingga terintegrasi dengan kamera dan monitor pengamatan di bagian panel pengoperasian.

Sistem lampu merupakan bagian utama dan komponen terpenting dari kontruksi rangkaian lampu LED bawah air, oleh karena itu banyak pertimbangan yang harus diperhatikan agar lampu LED bawah air dapat digunakan dengan baik dan bertahan lama. Salah satu faktor penting yang dipertimbangkan adalah dalam penggunaan material. RGB High Power LED 10 watt yang digunakan sebanyak 15 lampu, dimana pada setiap sisi terdiri dari 3 buah lampu yang dirangkai secara paralel. Lampu LED dipasang pada hollow aluminium persegi (lampu samping) dan plat aluminium (lampu bawah) dengan bantuan tube glue thermal adhesive yang berfungsi sebagai perekat sekaligus penghantar panas yang dihasilkan Lampu LED, sehingga panas yang dihasilkan oleh lampu terserap oleh aluminium. Oleh karena itu, penggunaan aluminium berfungsi sebagai peredam panas (heatsink) dan untuk memaksimalkan peredaman panas pada bagian dalam hollow aluminium ditambahkan sirip aluminium pada sisi dalam hollow aluminium, serta desain yang terbuka sebagai aliran air. 
Penggunaan material aluminium juga dinilai lebih tahan terhadap korosif dibandingkan dengan besi. Seperti yang dikemukakan Priyotomo (2008), bahwa logam aluminium umum digunakan di bidang penerbangan, otomotif dan sebagainya dikarenakan mempunyai ketahanan terhadap korosi atmosfer.

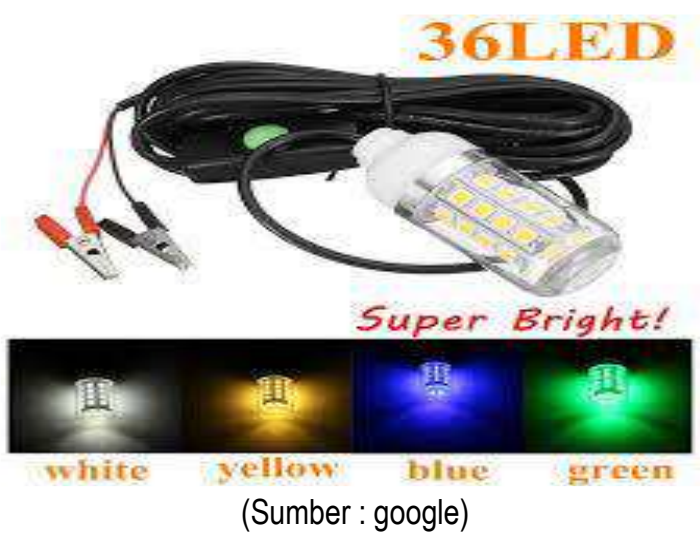

Gambar 1. Jenis LED

RGB High Power LED 10 watt yang telah terpasang disambungkan dengan driver RGB yang berfungsi sebagai stabilizer atau pengatur tegangan yang dihasilkan dari input tegangan sehingga input tegangan yang masuk ke lampu menjadi stabil. Tipe driver yang digunakan adalah Waterproof Adjustable Step Down CC-CV (QSKJ) LED Driver IN: DC.7-35V OUT:DC.2-30V. Adapun jumlah driver yang digunakan adalah sebanyak 9 buah, dimana pada lampu bagian atas setiap 6 buah lampu dihubungkan dengan 1 buah driver untuk setiap warnanya, sedangkan untuk bagian bawah setiap 3 buah lampu dihubungkan dengan 1 buah driver untuk setiap warnanya. Setelah semua komponen elektronika terangkai, untuk bagian kedap air digunakan resin untuk mengecor bagian lampu. Pada sistem lampu dibuat massive tidak ada rongga udara seperti semacam casing underwater bertujuan agar lampu lebih berat dan tenggelam sehingga cenderung lebih dapat stabil walaupun terkena arus. Hal ini didasarkan pada literatur yang menjelaskan bahwa justru cahaya terang yang tidak stabil/ berubahubah akan menakutkan bagi ikan (fickering light). Adanya kemungkinan arus kuat dan gelombang besar jelas akan mempengaruhi kedudukan lampu (Subani \& Barus, 1988). Makin besar gelombang makin besar pula flickering light yang terjadi dan makin besar hilangnya efisiensi sebagai daya penarik perhatian ikan-ikan maupun biota lainnya menjadi lebih besar karena ketakutan. Selain itu, pertimbangan lain yaitu apabila didesain semacam casing underwater akan ada kemungkinan embun di dalam lampu karena adanya ruang udara di dalamnya. Pengembunan bisa terjadi kondensasi udara dalam lampu. Bahan yang digunakan pada metode ini terdapat pada Tabel 1 dibawah ini :

Tabel 1. Bahan yang Digunakan

\begin{tabular}{lc}
\hline \multicolumn{1}{c}{ Nama Bahan } & Jumlah \\
\hline Lampu LED DC 12 V & 10 unit \\
Kabel Tahanan Air & 1 meter \\
Aki Basah & 24 volt \\
Lakban Perekat & 1 roll \\
Pipa Akrilik Bening & 5 meter \\
Pipa Paralon & 1 meter \\
Penyambung Paralon & 20 unit \\
Aluminium & 1 batang \\
\hline
\end{tabular}




\section{Hasil dan Pembahasan}

Dalam hal ini persiapan dimulai dari pengumpulan materi dengan cara mencari permasalahan pada masyarakat dibidang perikanan serta dari jurnal-jurnal dan artikel tentang kebutuhan masyarakat pesisir akan teknologi tepat guna yang mampu dimanfaatkan dan mudah dalam penggunaannya, untuk itu dibutuhkan persiapan matang dalam pembuatan penelitian lampu LED pemikat ikan ini. Dimana pada pembuatan lampu LED pemikat ikan ini membutuhkan proses yang cukup membutuhkan waktu yang lama dikarenakan lampu LED pemikat ini harus mampu memancarkan sinar yang terang di dalam air sehingga dapat menarik perhatian ikan-ikan yang hidup didasar ataupun di permukaan air. Adapun proses pembuatan lampu LED pemikat ikan ini dibagi menjadi 6 tahapan yaitu persiapan, pelaksanaan, produksi, prosedur kerja, pemasaran, dan analisa usaha.

\subsection{Persiapan}

Tahap ini merupakan tahap awal pada pembuatan rancangan lampu LED pemikat ikan dimana pada tahap ini mensurvey dan mencari barang-barang yang dibutuhkan seperti alat dan bahan dengan harga alat dan bahan yang lebih terjangkau dan dapat dijual dengan harga yang sesuai dengan pasar.

\subsection{Pelaksanaan}

Setelah selesai pada tahap persiapan serta barang dan alat yang dibutuhkan dalam pembuatan rancangan lampu LED pemikat ikan sudah didapatkan, dalam pembuatan rancangan lampu LED ini membutuhkan tahap pelaksanaan dimana pada tahap pelaksanaan ini pembuatan lampu LED pemikat ikan tidak membutuhkan waktu yang lama dalam pengerjaannya, namun dibuthkan ketelitian dalam pembuatan nya agar tidak terjadi permasalahan dalam pengoperasiannya.

\subsection{Produksi}

Pada tahap produksi ini sebagai uji coba kelayakan pertama akan dibuat sebanyak 1 set unit lampu LED pemikat ikan yang dibuat dengan sistem yang modern yang lebih efektif dan efisien.

\subsection{Prosedur Kerja}

Rencana desain awal lampu LED pemikat ikan dibangun untuk penggunaan di dalam air yang bertujuan untuk mengurangi pemudaran yang disebabkan perbedaan media rambat cahaya. Oleh karena itu pemilihan bahan juga sangat diperhatikan terutama untuk melindungi bagian dari lampu yang terendam dalam air. Hal senada dikemukakan oleh Callister (2004) \& Smith (1996) bahwa dalam merancang atau mendesain sebuah produk terdapat persyaratan terkait dengan sifat dari produk yang ingin dibuat, pemilihan material menjadi salah satu yang harus dipertimbangkan dan harus memperhatikan fungsi (function), batasan (constrain), tujuan (objective), dan variabel bebas (free variables). Selain itu lampu juga dirancang untuk memudahkan penggunanya atau nelayan dalam mendeteksi keberadaan ikan sehingga terintegrasi dengan kamera dan monitor pengamatan di bagian panel pengoperasian.

Sistem lampu merupakan bagian utama dan komponen terpenting dari kontruksi rangkaian lampu LED pemikat ikan, oleh karena itu banyak pertimbangan yang harus diperhatikan agar lampu LED pemikat ikan ini dapat digunakan dengan baik dan bertahan lama. Salah satu faktor penting yang dipertimbangkan adalah dalam penggunaan material. RGB High Power LED 10watt yang digunakan sebanyak 3 set lampu, dimana pada setiap sisi terdiri dari 3 buah lampu yang dirangkai secara paralel. Lampu LED dipasang pada hollow aluminium persegi (lampu samping) dan plat aluminium (lampu bawah) dengan bantuan tube glue thermal adhesive yang berfungsi sebagai perekat sekaligus penghantar panas yang dihasilkan Lampu LED, sehingga panas yang dihasilkan oleh lampu terserap oleh aluminium. Oleh karena itu, penggunaan aluminium berfungsi sebagai peredam panas (heatsink) dan untuk memaksimalkan peredaman panas pada bagian dalam hollow aluminium ditambahkan sirip aluminium pada sisi dalam hollow aluminium, serta desain yang terbuka sebagai aliran air. Penggunaan material aluminium juga dinilai lebih tahan terhadap korosif dibandingkan dengan besi. 
Seperti yang dikemukakan Priyotomo (2008) bahwa logam aluminium umum digunakan di bidang penerbangan, otomotif dan sebagainya dikarenakan mempunyai ketahanan terhadap korosi atmosfer.

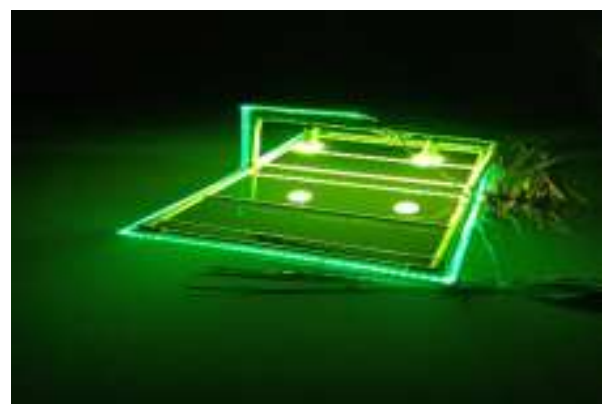

Gambar 2. LED

RGB High Power LED 10watt yang telah terpasang disambungkan dengan driver RGB yang berfungsi sebagai stabilizer atau pengatur tegangan yang dihasilkan dari input tegangan sehingga input tegangan yang masuk ke lampu menjadi stabil. Tipe driver yang digunakan adalah Waterproof Adjustable Step Down CC-CV (QSKJ) LED Driver IN: DC.7-35V OUT: DC.2-30V.

\subsection{Pemasaran}

Pada tahap ini dibutuhkan strategi khusus dalam melakukannya dikarenakan untuk sebuah produk baru yang modern sedikit sulit diterapkan pada masyarakat nelayan. Namun, pada target dasarnya Pemasaran lampu LED pemikat ikan ini ditujukan untuk para nelayan dan pengusaha perikanan atau perusahaan perikanan tangkap yang ada diseluruh Indonesia dengan sistem kerja yang lebih efisien dan dibutuhkan sosialisasi terhadap masyarakat nelayan dan lampu ini mampu membantu masyarakat khususnya masyarakat atau nelayan dengan alat tangkap Purse seine, Gill net, Bagan Apung, Bagan Tancap, dan lainnya.

3.6 Analisa Usaha

Dalam pelaksaan tahap Analisa usaha ini yang menjadi target pasar dalam pemasaran adalah masyarakat nelayan dan perusahaan perikanan tangkap yang berada diseluruh Indonesia. Dimana estimasi biaya produksi yang dikeluarkan sebanyak 1.000.000 rupiah dan akan di jual di pasar dengan harga 2.000.000 rupiah dengan mendapat selisih keuntungan sebanyak 1.000 .000 rupiah. Produk ini juga memiliki $\mathrm{B} / \mathrm{C}$ ratio dengan rumus :

\section{Keuntungan Produksi : Jumlah harga produksi $=\mathrm{b} / \mathrm{c}$ ratio}

\section{(Rp. $2.000 .000,-:$ Rp. $1.000 .000,-)=1.00$}

Maka dari itu b/c ratio diatas 1 dinyatakan produk layak dipasarkan dan mendapat keuntungan lebih.

a. Rugi /laba

$$
\begin{aligned}
\text { Rugi } & =\text { total penjualan }- \text { total biaya variabel } \\
& =\text { Rp. } 2.000 .000-\text { Rp. } 1.000 .000 \\
& =\text { Rp. } 1.000 .000,-
\end{aligned}
$$

Hasil di atas menunjukan bahwa dalam sekali produksi keuntungan atau laba yang diproleh sebesar Rp. 2.500.000,-

$$
\begin{aligned}
& \text { b. Break Event point } \\
& \text { BEP produk }=\text { total biaya }: \text { harga penjualan } \\
&=1.000 .000: 2.000 .000 \\
&=0.50 \\
& \text { BEP Harga }=\text { total biaya }: \text { jumlah produksi } \\
&=1.000 .000: 1 \\
&=1.000 .000,-
\end{aligned}
$$

Maka dalam produksi 1 unit usaha tersebut berada di titik untung dan tidak rugi sedangkan jika harga barang Rp. 2.000.000,- maka usaha tersebut tidak untung dan tidak rugi. 


\section{Kesimpulan}

Dalam menjalankan suatu usahsa dan pembauatan suatu produk penelitian dibutuhkan ketekunan, ide, strategi, dan kerja keras individu atau kelompok serta keinginan dari setiap individu untuk dapat maju dan menghasilkan sebuah produk teknologi tepat guna yang efiktif, efisien, dan murah dengan kedisiplinan dalam menjalankan suatu bisnis atau usaha. Pembuatan lampu LED pemikat ikan ini dapat dikembangkan dan ditingkatkan untuk meningkatkan mental dan jiwa setiap individua tau kelompok untuk dapat menciptakan suatu karya inovasi berupa produk penelitian dengan teknologi tepat guna yang dapat digunakan diera global. Hasil analisa usaha produk juga menjukkan bahwa lampu LED pemikat ikan ini dapat menghasilkan keuntungan dan layak untuk dijalankan sehigga produk inovasi ini dapat digunakan oleh perusahaan perikanan dan nelayan di Indonesia.

\section{Daftar Pustaka}

Baskoro MS. (2000). Capture Process of The Floated Bamboo-Platform Liftnet with Light Atrraction. Doctoral Course of Marine Scienses and Technology: Graduate School of Fisheries, Tokyo University of Fisheries.

Ben Yami BM. (1976). Fishing with Light. England: Published by Arrangement with FAO of The United Nations by Fishing News Books Ltd. Surrey.

Callister Jr. (2004). An Introduction Materials Science and Engineering. Wiley.

Haygreen, Bowyer. (1987). Hasil Hutan dan IImu Kayu. Yogyakarta: Gadjah mada University Press.

Hua LT, Xing J. (2013). Research on LED fishing light. Research Journal of Applied Sciences, Engineering and Technology. 5 (16):4138-4141.

Shen SC, Huang HJ. (2012). Design of LED Fish Lighting Attractors Using Horizontal/Nertical LIDC Mapping Method. Optics Express. Vol. 20.

Subani B. (1989). Alat Penangkapan Ikan dan Udang di Indonesia. Jurnal Penelitian Perikanan Laut. Nomor 50 Tahun 1988/1999. Edisi Khusus. Jakarta: Balai Penelitian Perikanan Laut, Badan Penelitian Perikanan Laut, Departemen Pertanian.

Sudirman, Baskoro MS, Purbayanto A, Safrudin, \& Suratman. (2006). Hubungan antara Kecerahan Perairan dan Kecepatan Arus dengan Hasil Tangkapan dan Pengoperasian Bagan Rambo di Selat Makassar. Jurnal IImiah Sorihi. 1 (5):82-104.

Smith WF. (1996) . Principle of Materials Science and Engineering. Mc Graw Hill.

Wollburg P, Mills E. (2013). Alternatives to Fuel-Based Lighting for Night Fishing Field Tests of Lake and Ocean Applications in East Africa. Technical Report. USA: University of California. 